\title{
Neutrophil Elastase Cleaves C3bi on Opsonized Pseudomonas as well as CR1 on Neutrophils to Create a Functionally Important Opsonin Receptor Mismatch
}

Michael F. Tosi, Harriet Zakem, and Melvin Berger

Department of Pediatrics, Case Western Reserve University School of Medicine, Cleveland, Ohio 44106

\begin{abstract}
Neutrophil elastase has been implicated as a factor that impairs local host defenses in chronic Pseudomonas aeruginosa (Pa) lung infection in cystic fibrosis (CF). We recently showed that this enzyme cleaves the $\mathrm{C} 3 \mathrm{~b}$ receptor, $\mathrm{CR} 1$, from neutrophils (PMN) in the lungs of infected CF patients. The C3bi receptor on these cells, $\mathrm{CR3}$, is resistant to elastase. We now show that purified neutrophil elastase markedly impairs complement-mediated PMN-Pa interactions including phagocytosis of opsonized $\mathrm{Pa}$, stimulation by opsonized $\mathrm{Pa}$ of $\mathrm{PMN}$ superoxide production, and killing of opsonized Pa by PMN. When PMN and opsonized Pa were treated separately with elastase, additive levels of inhibition were observed in each of the above assays. The effects on the bacteria were due to cleavage of the bound $\mathrm{C} 3 \mathrm{bi}$ from the surface of opsonized $\mathrm{Pa}$ by neutrophil elastase. C3bi was also cleaved by pseudomonas elastase, or bronchoalveolar lavage fluid from CF patients with chronic $\mathrm{Pa}$ lung infection. Inhibitors of neutrophil elastase eliminated C3bi cleavage by BAL fluid, while inhibitors of pseudomonas elastase had no effect. Blocking CR1 and CR3 on PMN with specific monoclonal antibodies reduced phagocytosis of opsonized $\mathrm{Pa}$ to an extent similar to that caused by elastase cleavage of CR1 on PMN and C3bi on Pa. We conclude that neutrophil elastase in the lungs of chronically infected CF patients cleaves C3bi from opsonized $\mathrm{Pa}$ as well as CR1 from PMN, creating an "opsonin-receptor mismatch" that severely impairs complement-mediated phagocytic host defenses against these bacteria. (J. Clin. Invest. 1990. 86:300-308.) Key words: cystic fibrosis • chronic inflammation - alpha-1-antitrypsin • phagocytosis • complement
\end{abstract}

\section{Introduction}

Chronic lung infection with Pseudomonas aeruginosa $(\mathrm{Pa})^{1}$ continues to be a major cause of morbidity and mortality in patients with cystic fibrosis (CF) (1). Since no systemic host

This work was presented in part at the annual meeting of the Society for Pediatric Research, May 1989, Washington DC, and an abstract of this presentation was published in the meeting program.

Address reprint requests to Michael F. Tosi, M.D., Rainbow Babies \& Childrens Hospital, 2101 Adelbert Road, Cleveland, OH 44106.

Received for publication 29 September 1989 and in revised form 19 January 1990

1. Abbreviations used in this paper: BAL, bronchoalveolar lavage; CF, cystic fibrosis; LY, lucifer yellow; NHS, pooled normal human serum; $\mathrm{Pa}$, Pseudomonas aeruginosa.

J. Clin. Invest.

(c) The American Society for Clinical Investigation, Inc. 0021-9738/90/07/0300/09 \$2.00

Volume 86, July 1990, 300-308 defense defect has been documented in these patients, it seems likely that local factors cause impairments in pulmonary host defenses. Several specific local abnormalities have been described (2-5). Among these is our recent observation that polymorphonuclear leukocytes (PMN) recovered from the lungs of CF patients by bronchoalveolar lavage (BAL), are relatively deficient in expression of the $\mathrm{C} 3 \mathrm{~b}$ receptor, $\mathrm{CR} 1$ (5). This deficiency of CR1 occurs in the face of normal upregulation of the C3bi receptor (CR3) and appears to be caused by proteolytic cleavage, since treatment of blood PMN with BAL supernatants from CF patients resulted in marked loss of CR1, but not CR3, from their surfaces. Pretreating the BAL fluid with the serine protease inhibitor, PMSF or alpha-1-antitrypsin completely eliminated CR 1 loss (5), implicating neutrophil elastase as the responsible enzyme in this milieu.

Cleavage of CR1 by elastase is likely to impair C3b-mediated phagocytosis, but would not affect interactions via $\mathrm{C} 3 \mathrm{bi}$, the other major opsonic $\mathrm{C} 3$ fragment, since the receptor for the latter, CR3, is elastase resistant $(5,6)$. However, bound C3bi itself is highly sensitive to proteases, as indicated by previous studies with sheep erythrocytes, while $\mathrm{C} 3 \mathrm{~b}$ is resistant (7). Effects of proteases on C3bi bound to bacteria have not been reported, but elastase cleavage of this opsonic fragment could impair phagocytosis via CR3. Therefore, we studied the effects of neutrophil elastase in vitro on interactions between PMN and opsonized Pa. Elastase caused marked impairments of PMN-Pa interactions, including attachment, phagocytosis, stimulation of PMN superoxide production, and bacterial killing by PMN. We found that this enzyme cleaves $\mathrm{C} 3 \mathrm{bi}$ bound to $\mathrm{Pa}$, in addition to cleaving $\mathrm{CR} 1$ on $P M N$, and that both actions of elastase contribute to the impaired complement-mediated PMN-Pa interactions. Finally, we showed that neutrophil elastase accounts for virtually all of the C3bi-cleaving activity in BAL fluid from chronically infected CF patients. These studies demonstrate that elastase causes an opsonin-receptor mismatch which could severely impair complement-dependent phagocytic host defenses in the lung in CF. Since elastase can also cleave the Fc portion of IgG antibodies (3), such an impairment in complement-dependent phagocytosis takes on even greater significance. It is possible that inhibitors of neutrophil elastase could be used therapeutically to limit or reverse this pathologic effect and thus enhance clearance of bacteria from the lung.

\section{Methods}

Reagents. Neutrophil elastase (human leukocyte elastase) was purchased from Elastin Products (Pacific, MO). Pseudomonas elastase was purchased from Nagase Biochemicals, Ltd. (Kyoto, Japan). $\mathrm{N}$-formyl-methionyl-leucyl-phenylalanine (FMLP), lucifer yellow VS (4amino- $N$-[3-(vinylsulfonyl)-phenyl]naphthalimide-3,6-disulfonate), PMSF, phosphoramidon $(N-(\alpha$-rhamnopyranosyloxyhydroxyphosphinyl)-L-leucyl-L-tryptophan), lucigenin (bis- $N$-methyl acridinium nitrate), and p-nitro-phenylphosphate were all purchased from Sigma 
Chemical Co. (St. Louis, MO). Alpha-1-antitrypsin (Prolastin ${ }^{\circledR}$ ) was a gift of Cutter Biologicals (West Haven, CT). Haemophilus influenzae type b lipopolysaccharide (LPS) from strain Egan was the gift of Dr. Thomas Inzana (Blacksburg, VA).

Bacterial strains. Two isolates of $\mathrm{Pa}$ from pulmonary secretions of patients with CF, one mucoid (strain M57-15) and the other nonmucoid (strain 121-31) were obtained from the Cystic Fibrosis Core Center at Case Western Reserve University. Additional bacterial isolates included a serum-sensitive strain of Escherichia coli (ATCC, strain 13,615), Staphylococcus aureus (ATCC, strain 25,923), and clinical respiratory isolates of Streptococcus pneumoniae type 14 and untypable Haemophilus influenzae. For assays of phagocytosis, PMN superoxide production, and bound complement fragments (see below) bacteria, from overnight broth cultures, were heat-killed at $60^{\circ} \mathrm{C}$ for 30 min, washed twice with PBS, and frozen in suspension at $-80^{\circ} \mathrm{C}$ for later use. Confirmatory studies with live bacteria gave identical results.

We noted reversion of our mucoid strain of $\mathrm{Pa}$ (M57-15) to the nonmucoid phenotype in only a very few instances. Data from assays with M57-15 were reported only from experiments in which mucoidy of this strain was confirmed.

Preparation of serum. A pool of fresh serum, prepared as previously described from six healthy adult donors and designated normal human serum (NHS), was aliquoted and frozen immediately at $-80^{\circ} \mathrm{C}$ for subsequent use (8). Hemolytic complement activity in representative thawed aliquots was confirmed as previously described (9). For control experiments to rule out the potential contribution of antibodies in NHS that could react with $\mathrm{Pa}$, aliquots of NHS were adsorbed in the cold with an excess of organisms from the strain of $\mathrm{Pa}$ to be opsonized. This reduced hemolytic complement activity by $<5 \%$.

Opsonization and protease treatment of bacteria. Bacteria were mixed with $20 \%$ NHS in PBS and shaken in a water bath at $37^{\circ} \mathrm{C}$ for 45 min, then washed three times in PBS, and resuspended at the appropriate concentration for each subsequent assay. For some experiments, varying concentrations of neutrophil elastase, Pseudomonas aeruginosa elastase, or BAL supernatants either from CF patients with chronic $\mathrm{Pa}$ lung infection or from healthy adult volunteers were used to treat bacteria after opsonization. The BAL supernatants were provided by the CF Core Center (5) and stored in aliquots at $-80^{\circ} \mathrm{C}$. Some aliquots of BAL fluid were pre-incubated for $15 \mathrm{~min}$ with alpha-1-antitrypsin $(33 \mu \mathrm{g} / \mathrm{ml})$, PMSF ( $1 \mathrm{mM})$, EDTA $(5 \mathrm{mM})$, or phosphoramidon $(0.2$ $\mathrm{mM})$, to inhibit different classes of proteases (5).

Isolation of peripheral blood neutrophils and treatment with elastase or monoclonal antibodies to complement receptors. PMN were purified from heparinized whole blood from healthy adult volunteers using discontinuous gradients of Percoll (Pharmacia Fine Chemicals, Piscataway, NJ) and hypotonic lysis of residual red cells as previously described (10). This technique produced PMN suspensions of $>95 \%$ purity and viability. Before use in most of the assays described below PMN were preincubated at $37^{\circ} \mathrm{C}$ for $60 \mathrm{~min}$ with $10^{-8} \mathrm{M}$ FMLP to upregulate surface expression of complement receptors (10).

Lyophilized human leukocyte elastase $(875 \mathrm{U} / \mathrm{mg}$ ) was dissolved in distilled water at $1 \mathrm{mg} / \mathrm{ml}$, stored in small aliquots at $-80^{\circ} \mathrm{C}$, and thawed immediately before use. Elastase was added to PMN suspensions either simultaneously with FMLP or at varying intervals before the end of the 60 -min incubation. It should be noted that in initial experiments to evaluate the effects of elastase on PMN-Pa interactions, opsonized $\mathrm{Pa}$ were added to elastase-treated PMN suspensions without first washing out the enzyme. Thus, PMN and opsonized Pa were both exposed to the enzyme, as they would be in vivo. In additional experiments, PMN or opsonized $\mathrm{Pa}$ were exposed to elastase separately, then washed before mixing, to compare the effects of elastase treatment of one vs. the other on their subsequent interactions.

For experiments designed to compare the effect of specific blockade of CR 1 or CR3 on PMN with the effect of elastase cleavage of CR1 on PMN or C3bi bound to Pa (see below), PMN were preincubated with saturating concentrations of MAb to CR 1 (from hybridoma clone 3D9; supplied by Dr. John O'Shea, Bethesda, MD) or CR3 (antiMol/CD1 lb, clone 44; supplied by Dr. Robert Todd, Ann Arbor, MI). As a control, we used a MAb that binds to FcR II, the $40-\mathrm{kD}$ Fc receptor on PMN (anti-CDw32; clone IV.3; supplied by Drs. Michael Fanger and Paul Guyre, Hanover, NH) (11).

FACS analysis of PMN complement receptor expression was performed using monoclonal antibodies to CR1 and CR3, followed by fluorescein-conjugated goat $\mathrm{F}(\mathrm{ab})^{\prime} 2$ anti-mouse IgG (Cappel Laboratories, Malvern, PA), and a FACS analyzer (Becton Dickinson \& Co., Mountain View, CA) as previously described (12). Results were expressed as the arithmetic mean fluorescence of $10^{4} \mathrm{PMN}$ after subtraction of background values from identically treated cells incubated with HBSS or an irrelevant control MAb in place of anti-receptor MAbs.

Attachment/phagocytosis of bacteria by PMN. Bacteria were labeled with the fluorescent ligand lucifer yellow (LY) by incubation for $1 \mathrm{~h}$ at room temperature with LY, as described by Sveum et al. (13). After opsonization as described above, bacteria were treated at $37^{\circ} \mathrm{C}$ for $30 \mathrm{~min}$ with protease or control buffer. After three washes in PBS, 5 $\times 10^{7}$ bacteria in HBSS $+0.1 \%$ gelatin (HBSS-gel) were added to 2 $\times 10^{6} \mathrm{PMN}$ in a final volume of $0.3 \mathrm{ml}$ of HBSS-gel. Mixtures were agitated gently at $37^{\circ} \mathrm{C}$ for $20 \mathrm{~min}, 2.0 \mathrm{ml}$ cold PBS was then added, and PMN were separated from most of the free bacteria by three differential centrifugations at $180 \mathrm{~g}$ for $5 \mathrm{~min}$. The PMN were resuspended in PBS and analyzed by fluorescence flow cytometry with volume discriminators set to eliminate any remaining free bacteria from the analysis. The arithmetic mean fluorescence of $10^{4} \mathrm{PMN}$ represented the extent of PMN uptake of fluorescent bacteria. Attachment alone was distinguished from attachment plus phagocytosis by incubating identical mixtures at $0^{\circ} \mathrm{C}$, or in the presence of $5 \mu \mathrm{g} / \mathrm{ml}$ cytochalasin B at $37^{\circ} \mathrm{C}$. Either of these treatments allows attachment but not ingestion $(13,14)$. Phagocytosis was confirmed in representative experiments by fluorescence microscopy. In preliminary experiments, bacteria that were labeled with LY without earlier heat-killing were taken up by PMN to an extent similar to heat-killed, LY-labeled bacteria.

Stimulation of PMN superoxide production. Superoxide $\left(\mathrm{O}_{2}^{-}\right)$production by PMN in response to opsonized bacteria and other stimuli was determined by measuring the chemiluminescence caused by the superoxide dismutase (SOD)-inhibitable reduction of lucigenin (bis$N$-methyl acridinium nitrate; Sigma Chemical Co.) $(15,16)$. PMN $\left(10^{6}\right)$ were mixed with $10^{8}$ opsonized bacteria in a final volume of 1.0 $\mathrm{ml} \mathrm{PBS}$ containing $10^{-5} \mathrm{M}$ lucigenin at $37^{\circ} \mathrm{C}$. Control stimuli included phorbol myristate acetate (PMA; $1.0 \mu \mathrm{g} / \mathrm{ml}$ ) and lipopolysaccharide from Haemophilus influenza type b (LPS; $100 \mu \mathrm{g} / \mathrm{ml}$ ). Chemiluminescence from these mixtures was measured at 5 -min intervals for $45 \mathrm{~min}$ in an LKB 1251 automated temperature-controlled luminometer (LKB Instruments, Inc., Bromma, Sweden) equipped for continuous stirring during measurements. The addition of SOD (100 $\mu \mathrm{g}$; Sigma Chemical Co.) caused $>95 \%$ inhibition of light emission, confirming the specificity of the reaction for superoxide. Results were expressed as the peak chemiluminescence $(\mathrm{mV})$ measured during the $45-\mathrm{min}$ incubation.

$P M N$ bactericidal assay. Since our $\mathrm{Pa}$ isolates were serum sensitive, as are most $\mathrm{Pa}$ respiratory isolates in CF (17), bacteria to be used in killing assays were preopsonized with serum that had been depleted of C5 using an immunoadsorbent prepared with goat antibody to human C5 (Atlantic Antibodies, Scarborough, ME). This eliminated killing of bacteria by late complement components, without significantly reducing deposition of $\mathrm{C} 3$ fragments (Tosi, M. F., unpublished data). These bacteria (2.0-2.5 $\left.\times 10^{7} \mathrm{cfu}\right)$ were washed in PBS, resuspended in $1.0 \mathrm{ml}$ of a mixture of equal volumes of HBSS-gel and tryptic soy broth, then added to $5 \times 10^{6} \mathrm{PMN}$ or buffer control to a final volume of $1.5 \mathrm{ml}$ in HBSS-gel. Aliquots were removed immediately and after 30 and 90 min of tumbling at $12 \mathrm{rpm}$ at $37^{\circ} \mathrm{C}$, and $\mathrm{cfu} / \mathrm{ml}$ were determined by serial dilution in sterile water and quantitative spread plating on TSA (18). The change in cfu/ml over $90 \mathrm{~min}$ for each experimental condition was compared to the change over the same period for the control mixture without PMN to determine the extent of killing by the PMN.

Enzyme immunoassay of $C 3$ fragments bound to opsonized $P$. aeruginosa. A modification of a previously described method for measuring $\mathrm{C} 3$ bound to $\mathrm{Pa}(19)$ was used to measure specific $\mathrm{C} 3$ fragments bound to these organisms. Bacteria were heat-killed and opsonized as 
described above, then incubated with buffer alone, purified proteases, or CF BAL supernatants for $30 \mathrm{~min}$ at $37^{\circ} \mathrm{C}$. After washing twice again with PBS, $10^{8}$ bacteria were pelleted at $10,000 \mathrm{~g}$ for $5 \mathrm{~min}$, and then resuspended for $30 \mathrm{~min}$ in $0.2 \mathrm{ml}$ of a 1:500 dilution of either a MAb against a neoantigen on $\mathrm{C} 3 \mathrm{bi}$ that is not expressed on other $\mathrm{C} 3$ fragments or a MAb against $C 3 d$ that recognizes all bound C3d-containing fragments (C3b, C3bi, and C3d), both from Cytotech (San Diego, CA). Binding of these antibodies was detected using an alkaline phosphatase-conjugated goat anti-mouse IgG, followed by resuspension of bacteria overnight in $1 \mathrm{mg} / \mathrm{ml}$ p-nitrophenyl phosphate (Sigma Chemical Co.). The resulting supernatants were transferred to 96-well microtiter plates, and the $A_{410}$ was measured with an automated Dynatech MR600 Microplate Reader (Dynatech Laboratories, Alexandria, VA). Background values were determined with unopsonized bacteria and subtracted to obtain the net absorbance values reported. In preliminary experiments, deposition of $\mathrm{C} 3$ fragments was comparable with live vs. heat-killed $\mathrm{Pa}$ and for unlabeled vs. $\mathrm{LY}$-labeled $\mathrm{Pa}$.

\section{Results}

Effects of elastase on PMN complement receptor expression. As shown in Fig. $1 A$, there was a marked time- and concentration-dependent decrease in surface CR 1 expression caused by treatment of FMLP-stimulated peripheral blood PMN with neutrophil elastase. A $50 \%$ decrease was observed with 10 $\mu \mathrm{g} / \mathrm{ml}$ elastase for $20 \mathrm{~min}$, and a $90 \%$ decrease was caused by $30 \mu \mathrm{g} / \mathrm{ml}$ of elastase for $20 \mathrm{~min}$. As shown in Fig. $1 \mathrm{~B}, \mathrm{CR} 3$ expression was not affected by elastase at any concentration or duration of exposure. Consistent with previous studies $(5,11)$ the values for CR3 expression in the absence of elastase $(0 \mathrm{~min}$ of exposure) represent a sixfold upregulation of surface CR3 compared to PMN that were not preincubated with FMLP (not shown). No effect of elastase on this action of FMLP was observed. Thus, elastase did not actually interfere with the activation of the cells by FMLP. The results of these experiments were used to choose appropriate concentrations and durations of PMN exposure to elastase for subsequent assays. Note that for the first groups of experiments described below for each assay of PMN-Pa interactions, opsonized bacteria

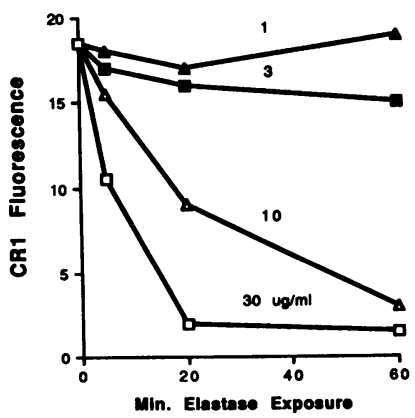

B

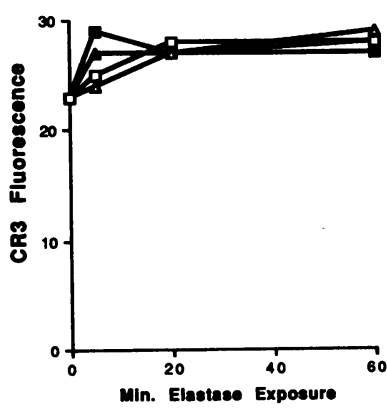

Figure 1. Time- and concentration-dependent cleavage of PMN CR1, but not CR3, by neutrophil elastase. Aliquots of $5 \times 10^{6} \mathrm{PMN}$ in $0.5 \mathrm{ml} \mathrm{HBSS} / 0.1 \%$ gelatin were incubated at $37^{\circ} \mathrm{C}$ with $10^{-8} \mathrm{M}$ FMLP for $60 \mathrm{~min}$. During this incubation, elastase was added at final concentrations of $1(\Delta), 3(\square), 10(\Delta)$, and $30(\square) \mu \mathrm{g} / \mathrm{ml}$ for the durations indicated. Cells were washed, and aliquots from each incubation condition were stained with monoclonal antibodies and analyzed by fluorescence flow cytometry for surface CR1 $(A)$ and $C R 3$ $(B)$. The mean fluorescence of 10,000 cells was corrected for background obtained using an irrelevant MAb. were added to elastase-treated PMN while the elastase was still present, so that both PMN and bacteria were exposed to the enzyme.

Effects of elastase on PMN attachment/phagocytosis of $L Y$-stained opsonized $P a$. Fig. 2 shows the results of a representative phagocytosis experiment showing individual FACS histograms for PMN that have been incubated with opsonized or unopsonized $\mathrm{LY}$-labeled $\mathrm{Pa}$. In this experiment, carried out at $37^{\circ} \mathrm{C}$, uptake of bacteria by $\mathrm{PMN}$ is measured as PMN fluorescence and may include attachment without ingestion as well as phagocytosis. The quantitative contribution of attachment without ingestion is $\sim 25 \%$ of total uptake, as assessed below (Fig. 3). Curve $A$ of Fig. 2 shows the low PMN fluorescence that results from uptake of unopsonized $\mathrm{Pa}$ by control PMN, while curve $B$ shows the marked increase in mean fluorescence of control PMN that have been incubated with opsonized $\mathrm{Pa}$. The results, shown here on a logarithmic scale, reveal that opsonization of the bacteria increased their uptake by PMN from a mean of 3.2 to 50.5 fluorescence units. This demonstrates the dependence on opsonization for optimal phagocytosis in this system. Curve $C$ shows the results obtained with PMN that had been treated with $10 \mu \mathrm{g} / \mathrm{ml}$ of elastase for $60 \mathrm{~min}$ before adding opsonized bacteria, and indicates that PMN uptake of bacteria was reduced by $65 \%$ compared to curve $B$ in this representative experiment. Fig. 3 shows the composite results of four separate experiments using both mucoid and nonmucoid strains of $\mathrm{Pa}$ in identical assays. As shown, for experiments done at $37^{\circ} \mathrm{C}$ there was nearly $50 \%$ reduction in phagocytosis of $\mathrm{Pa}$ induced by elastase treatment of PMN for both mucoid and nonmucoid strains. Experiments carried out at $0^{\circ}$, or in the presence of cytochalasin $B$, to measure attachment alone, showed similar 50\% decreases in bacterial attachment due to elastase treatment of the PMN, and demonstrated that only $\sim 25 \%$ of the total uptake of opsonized bacteria by control PMN at $37^{\circ} \mathrm{C}$ was due to attachment without ingestion. Thus, treatment with elastase sufficient to cause cleavage of $90 \%$ of PMN CR 1 (Fig. 1) resulted in a distinct functional impairment in attachment and phagocytosis of opsonized $\mathrm{Pa}$ by these cells. Control experiments in which we opsonized $\mathrm{Pa}$ with NHS pre-adsorbed in the cold with excess $\mathrm{Pa}$ organisms yielded identical results (not shown); thus, anti-Pa antibody did not contribute to the phagocytosis results or to the observed effects of elastase. Additional experi-

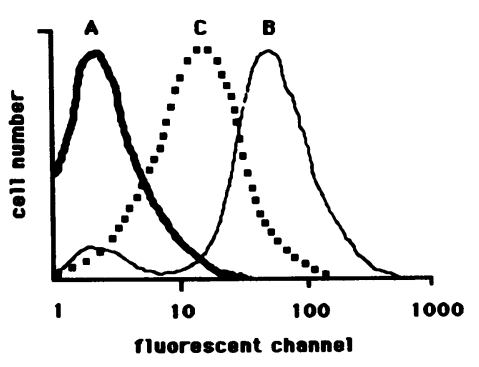

Figure 2. Effect of elastase on uptake of opsonized Pa by PMN. Heat-killed, lucifer yellow-stained $\mathrm{Pa}$ from a mucoid strain were opsonized in $20 \%$ NHS for $45 \mathrm{~min}$ at $37^{\circ} \mathrm{C}$. After washing, $5 \times 10^{7} \mathrm{~Pa}$ were added to $2 \times 10^{6} \mathrm{PMN}$ that had been treated with FMLP for $60 \mathrm{~min}$ in the presence or absence of elastase $(10 \mu \mathrm{g} / \mathrm{ml})$. These mixtures were slowly rotated at $37^{\circ} \mathrm{C}$ for 20 min, and the PMN were washed before being analyzed by fluorescence flow cytometry. Representative fluorescence histograms $(10,000$ cells) for control PMN incubated with nonopsonized $\mathrm{Pa}(A$; - ), control PMN incubated with opsonized $\mathrm{Pa}(B ;-)$, and elastase treated $\mathrm{PMN}$ incubated with opsonized $\mathrm{Pa}(C ; \cdots \cdots)$ are shown. 


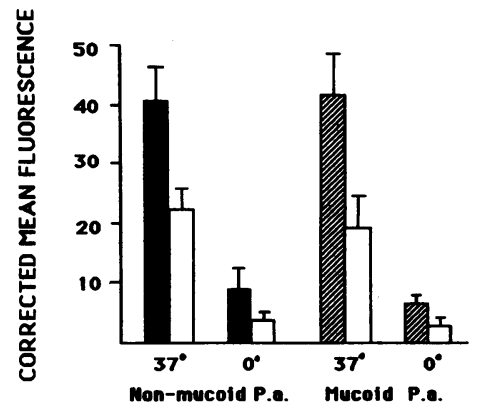
phagocytosis. Each result shown is the mean $\pm S E$ of four separate experiments in which values for phagocytosis of opsonized nonmucoid (घ) or mucoid (घ) Pa by control PMN were compared with the corresponding value for elastase-treated PMN ( $\square$ ). For all experiments comparing control vs. elastase treatment, $P<0.01$ by $t$ test.

ments using NHS heated at $56^{\circ} \mathrm{C}$ for 30 min (not shown) confirm that opsonization in this system is complement dependent.

Effects of elastase on PMN phagocytosis of other bacterial pathogens. We also measured the effects of elastase on PMN phagocytosis of $E$. coli, $S$. aureus, $H$. influenzae, and $S$. pneumoniae type 14, and the results are shown in Fig. 4. Differences in apparent uptake by control PMN among the four bacterial species (Fig. 4, solid bars) were at least partly due to interspecies differences in the ability of the bacteria to bind the fluorescent label (data not shown). In experiments identical to those above which demonstrated that elastase caused $52 \pm 14 \%$ decrease in phagocytosis of $\mathrm{Pa}$, we found that elastase treatment decreased the phagocytosis of these other species by 29-67\%. Thus, the inhibition of PMN-bacteria interactions by exogenous elastase was not specific for $\mathrm{Pa}$, but acted on opsonins and/or phagocyte receptors that are relevant to a range of bacterial pathogens.

Effects of elastase on stimulation by $\mathrm{Pa}$ of $\mathrm{PMN}_{2}^{-}$production. As shown in Fig. 5, there was a 45-50\% decrease in the $\mathrm{O}_{2}^{-}$ produced by elastase-treated PMN compared to control PMN when stimulated by opsonized $\mathrm{Pa}$, either the mucoid or nonmucoid strain $(P<0.01)$. In contrast, the $\mathrm{O}_{2}^{-}$response to other stimuli such as phorbol myristate acetate (PMA) and LPS was not affected by elastase. The latter findings demonstrated that elastase did not interfere with the actual mechanisms of $\mathrm{O}_{2}^{-}$

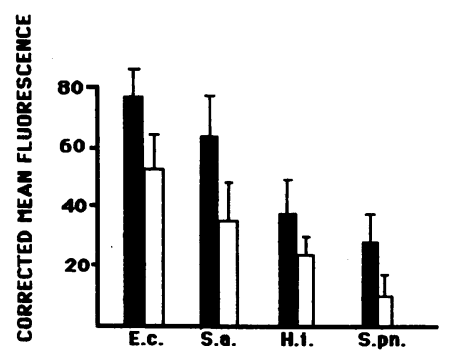

Figure 4. Effect of elastase on phagocytosis by PMN of other bacterial species. Experiments were performed exactly as described for Fig. 2. E. coli (E.c.), S. aureus (S.a.), untypable $H$. influenzae (H.i.), and $S$. pneumoniae, type 14 (S.pn.) were heat killed, LY-stained, and opsonized. Bacteria were mixed with control ( $\square$ ) or elastase-treated (口) PMN for 20 min as described. The mean fluorescence of 10,000 PMN was determined by flow cytometry. The results of four separate experiments (mean $\pm \mathrm{SE}$ ) are shown. Inhibition of phagocytosis by elastase treatment was $29 \pm 5 \%$ for E.c. $(P<0.05)$, $38 \pm 6 \%$ for S.a. $(P<0.05), 32 \pm 4 \%$ for H.i. $(P<0.05)$, and $67 \pm 12 \%$ for S.pn. $(P<0.01)$.

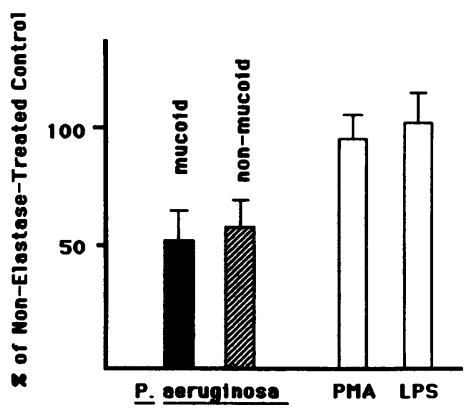

Figure 5. Effect of elastase on PMN superoxide production induced by opsonized $\mathrm{Pa}$ and other stimuli. PMN were incubated with $10^{-8} \mathrm{M}$ FMLP for $60 \mathrm{~min}$ in the presence or absence of $10 \mu \mathrm{g} / \mathrm{ml}$ of elastase. $10^{6}$ PMN were mixed with $10^{8}$ opsonized Pa (mucoid or nonmucoid) in a final volume of $1.0 \mathrm{ml}$ PBS that contained $0.05 \%$ BSA and $10^{-5} \mathrm{M}$ lucigenin. Chemiluminescence $(C L)$ was measured at $5 \mathrm{~min}$ intervals for $45 \mathrm{~min}$, and the peak $\mathrm{CL}(\mathrm{mV})$ during this period was determined. The value obtained for elastase-treated PMN with each stimulus was expressed as the percent of the value with the same stimulus for control PMN (mean $\pm \mathrm{SE}, n=4 ; P<0.01$ for decreased CL for both types of Pa). PMA (1 $\mu \mathrm{g})$ and LPS (100 $\mu \mathrm{g})$ were used as control stimuli in identical experiments.

production by PMN. Thus, the decrease in Pa-induced PMN $\mathrm{O}_{2}^{-}$production caused by elastase was apparently due to impairment of surface interactions between the PMN and the opsonized $\mathrm{Pa}$.

Effects of elastase on PMN killing of opsonized Pa. To confirm that the impairments in phagocytosis and $\mathrm{O}_{2}^{-}$production caused by elastase ultimately resulted in diminished killing of $\mathrm{Pa}$ by PMN, direct bactericidal assays were performed. We studied the effect of elastase on killing by incubating PMN with $30 \mu \mathrm{g} / \mathrm{ml}$ of elastase for $30 \mathrm{~min}$ rather than the $10 \mu \mathrm{g} / \mathrm{ml}$ for $60 \mathrm{~min}$ used in above assays, since we had observed a modest decrement in killing capacity of control PMN after 60 $\min$ vs. $30 \mathrm{~min}$ at $37^{\circ} \mathrm{C}$. The extent of CR1 cleavage was similar under both conditions, as shown in Fig. 1. As shown in Fig. 6, during incubation of opsonized $\mathrm{Pa}$ for $90 \mathrm{~min}$ in mixtures without PMN, there was a mean increase of $\sim 300 \%$ in $\mathrm{cfu} / \mathrm{ml}$. In mixtures that contained control PMN, there was a decrease in $\mathrm{cfu} / \mathrm{ml}$ of $\sim 50 \%$. In contrast, however, in mixtures that contained PMN treated with $30 \mu \mathrm{g} / \mathrm{ml}$ of elastase for $30 \mathrm{~min}$, there was actually a net increase in $\mathrm{cfu} / \mathrm{ml}$ of $\sim 180 \%$. To express the true extent of PMN killing of $\mathrm{Pa}$ in the face of

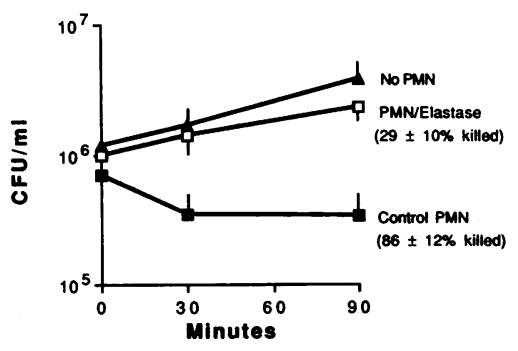

Figure 6. Effect of elastase on killing of opsonized $\mathrm{Pa}$ by PMN. Live $\mathrm{Pa}$ were opsonized in $20 \%$ NHS that had been depleted of C5 by immunoadsorption in the cold. Opsonized bacteria $\left(2.0-2.5 \times 10^{7} \mathrm{cfu} /\right.$ $\mathrm{ml}$ ) were suspended in $0.5 \mathrm{ml}$ TSB plus $0.5 \mathrm{ml}$ HBSS-gel, then added

to $5 \times 10^{6} \mathrm{PMN}$ that had been preincubated for $30 \mathrm{~min}$ with $(P M N)$ Elastase) or without (Control PMN) $30 \mu \mathrm{g} / \mathrm{ml}$ elastase. Bacterial suspensions without PMN (No PMN) served as a control for bacterial growth. The final volume of all mixtures was $1.5 \mathrm{ml}$. Aliquots were removed immediately and after 30 and 90 min of slow tumbling at $37^{\circ} \mathrm{C}$. Viable bacteria $(\mathrm{cfu} / \mathrm{ml})$ were counted by serial dilution and quantitative plating. Values shown represent mean \pm SE for five experiments. 
the increase in $\mathrm{cfu} / \mathrm{ml}$ that occurred under control conditions without PMN, we quantified killing of $\mathrm{Pa}$ by $\mathrm{PMN}$ at $90 \mathrm{~min}$ by subtracting values for $\mathrm{cfu} / \mathrm{ml}$ in mixtures with $\mathrm{PMN}$ from those for mixtures without PMN. We then expressed this difference as a percentage of the $\mathrm{cfu} / \mathrm{ml}$ in the mixtures without $P M N$. After adjusting for small differences in $\mathrm{cfu} / \mathrm{ml}$ at $0 \mathrm{~min}$, we determined that control PMN killed $86 \pm 12 \%$ of the $\mathrm{Pa}$,

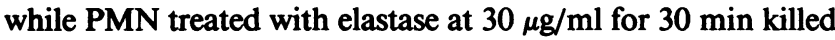
only $29 \pm 10 \%($ mean \pm SE, $n=5 ; P<0.001)$. The results shown are for the mucoid $\mathrm{Pa}$ strain; similar results were obtained with the nonmucoid strain of $\mathrm{Pa}$ (not shown). These studies thus confirmed the significance of the elastase-induced impairments in phagocytosis and $\mathrm{O}_{2}^{-}$production by directly demonstrating that they led to markedly decreased bacterial killing.

Effect of elastase treatment of opsonized pseudomonads alone vs. PMN alone. In all of the above experiments that assessed PMN-Pa interaction, the elastase used to pretreat the PMN remained present throughout the assay, so that both the PMN and the bacteria were exposed to the enzyme, as they would be in vivo. To determine whether the observed effects of elastase were due to actions on the bacteria themselves, rather than on the PMN, we performed parallel assays in which only the PMN or the bacteria were exposed to the enzyme. As shown in Fig. 7, the percent inhibition caused by elastase in each assay in the original sets of experiments (open bars) was reduced by about half when only the PMN were exposed to the enzyme (solid bars). Thus, it seemed likely that part of the effect of elastase on PMN-Pa interactions in the original experiments was due to its effects on the opsonized bacteria as well as on the PMN. As shown in the shaded bars, treatment of the opsonized bacteria alone with elastase also produced significant impairments in all three assays of PMN-Pa interaction $\left(P<0.01\right.$ for phagocytosis and $\mathrm{O}_{2}^{-}$production; $P<0.05$ for killing). Results were similar for mucoid and nonmucoid strains of $\mathrm{Pa}$.

Cleavage of C3bi bound to opsonized Pa by CF BAL supernatants and purified elastases. Previous studies have shown that human neutrophil elastase can cleave $\mathrm{C} 3$ bi on opsonized sheep erythrocytes, leaving the nonopsonic fragment C3d (7). This did not affect $\mathrm{C} 3 \mathrm{~b}$, the other major opsonic C3 fragment. Since our data suggested that some of the effects of elastase on PMN-Pa interactions were due to actions on the opsonized bacteria, we sought to determine whether this was due to cleav-

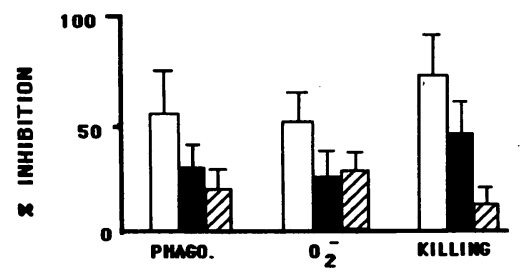

Figure 7. Effect of separate elastase treatment of PMN or opsonized $\mathrm{Pa}$ on $\mathrm{PMN}-\mathrm{Pa}$ interactions. The open bars represent the percent inhibition of phagocytosis, superoxide produc-

tion, or bacterial killing by PMN caused by elastase treatment of PMN in assays performed exactly as described above; that is, when PMN were treated with elastase $(10 \mu \mathrm{g} / \mathrm{ml}$ for $60 \mathrm{~min})$ and bacteria were added without first washing the PMN, so that both PMN and bacteria were exposed to the enzyme. The solid bars and hatched bars represent the percent inhibition by elastase in assays that were performed identically except that only the PMN or the opsonized bacteria, respectively, were exposed to elastase, then washed before mixing. The results shown represent the mean $\pm S E$ of three or four experiments performed with a mucoid strain of $\mathrm{Pa}$. age of C3bi from opsonized $\mathrm{Pa}$. We used an enzyme immunoassay with a monoclonal antibody against a neoantigen expressed only on C3bi, but not on C3b or C3d, to test the ability of neutrophil and Pseudomonas elastases and CF BAL supernatants to cleave $\mathrm{C} 3 \mathrm{bi}$ from opsonized $\mathrm{Pa}$. The results obtained with the mucoid strain of $\mathrm{Pa}$ are shown in Fig. 8. Results with the nonmucoid strain (not shown) were similar. After $30 \mathrm{~min}$ of exposure to neutrophil elastase at concentrations $>0.1 \mu \mathrm{g} / \mathrm{ml}$, C3bi on opsonized $\mathrm{Pa}$ was markedly reduced. About $45 \%$ of the C3bi was removed by $0.5 \mu \mathrm{g} / \mathrm{ml}$ and $\sim 90 \%$ by $1.0 \mu \mathrm{g} / \mathrm{ml}$. Pseudomonas elastase at similar concentrations produced an equivalent loss of anti-C3bi binding with $\sim 50 \%$ cleavage of C3bi occurring at $0.5 \mu \mathrm{g} / \mathrm{ml}$. When CF BAL supernatants were used as a potential source of proteases to treat opsonized $\mathrm{Pa}$, a concentration-dependent loss of bound $\mathrm{C} 3 \mathrm{bi}$ was also observed with a 1:10 dilution producing $>90 \%$ cleavage of C3bi. BAL supernatants from healthy controls had no effect (not shown). Using a similar enzyme immunoassay with a monoclonal antibody directed against C3d that also interacts with $\mathrm{C} 3 \mathrm{~b}$ and $\mathrm{C} 3 \mathrm{bi}$, we found that none of the above sources of protease activity diminished the total number of C3d-containing fragments, even at concentrations of the pure enzymes up to $5 \mu \mathrm{g} / \mathrm{ml}$. These results are consistent with the conversion of bound C3bi to C3d by elastase, rather than with attack of the proteases on surface components of the bacteria to which $\mathrm{C} 3$ fragments are bound. Our results thus confirmed a specific mechanism by which the proteases could act on opsonized $\mathrm{Pa}$ to impair complement-mediated PMNbacterial interactions.

Nature of C3bi-cleaving activity in CF BAL supernatants. To determine whether the cleavage of bound C3bi by CF BAL supernatant was due to neutrophil or Pseudomonas elastase or both, we pretreated aliquots of BAL supernatants with various protease inhibitors before using 1:10 dilutions of these supernatants to treat opsonized bacteria. As shown in Fig. 9, pretreatment of these supernatants with the serine protease inhibitors, PMSF, or alpha-1-antitrypsin, completely blocked the cleavage of C3bi caused by a 1:10 dilution of BAL supernatant, whereas pretreatment with the metalloproteinase inhibitor,



Figure 8. Cleavage of $\mathrm{C} 3 \mathrm{bi}$ on opsonized $\mathrm{Pa}$ by purified elastases and CF BAL supernatants. Opsonized $\mathrm{Pa}\left(10^{8}\right)$ were incubated at $37^{\circ} \mathrm{C}$ for 30 min with neutrophil elastase (-), Pseudomonas elastase $(\cdots \cdots)$, or CF BAL supernatant $(--\cdot)$ at the indicated concentrations or dilutions. After washing, MAb to C3bi neoantigen or to C3d (binds C3b, C3bi, and C3d) was added, and the residual binding to the complement fragments was determined by incubation with alkaline phosphatase-conjugated goat anti-mouse antibody and measurement of substrate conversion by $O D$ at $410 \mathrm{~nm}$. Background was determined using unopsonized $\mathrm{Pa}$ in the same assay and was subtracted to derive the values shown in these representative experiments with mucoid Pa. 


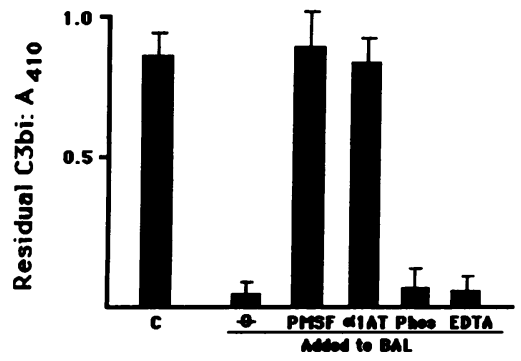

Figure 9. Effects of protease inhibitors on $\mathrm{C} 3 \mathrm{bi}$ cleavage by CF BAL supernatant. Opsonized $\mathrm{Pa}\left(10^{8}\right)$ were treated for $30 \mathrm{~min}$ at $37^{\circ} \mathrm{C}$ with a final 1:10 dilution of BAL supernatants from CF patients with chronic Pa lung infection. Supernatants had been aliquotted and stored at $-80^{\circ} \mathrm{C}$ and were thawed, then preincubated for $15 \mathrm{~min}$ with PMSF (1 mM), alpha-1-antitrypsin ( $\alpha 1 \mathrm{AT} ; 33 \mu \mathrm{g} / \mathrm{ml})$, phosphoramidon (phos; $0.2 \mathrm{mM}$ ), EDTA ( $5 \mathrm{mM}$ ), or a buffer control $(\theta)$. PBS was used in place of BAL supernatant to provide a positive control for bound C3bi (C). Bacteria were then assayed as above for residual bound C3bi. Results for each incubation condition are expressed as the mean $\pm \mathrm{SE}$ for four separate experiments, each performed with BAL supernatant from a different patient. PMSF and $\alpha 1$ AT significantly blocked C3bi cleavage compared to buffer control $(P<0.001)$. EDTA and phos. had no effect.

EDTA, or the Pseudomonas elastase inhibitor, phosphoramidon, did not block this cleavage at all. No diluent used with the inhibitors had any effect (not shown). Thus the activity in CF BAL supernatants that cleaves $\mathrm{C} 3 \mathrm{bi}$ on opsonized $\mathrm{Pa}$ is a serine protease, consistent with neutrophil elastase, rather than a metalloprotease such as Pseudomonas or macrophage elastase.

Comparative sensitivity to elastase of CR1 vs. C3bi. The above studies suggested that $\mathrm{C} 3 \mathrm{bi}$ on opsonized $\mathrm{Pa}$ was more sensitive than CR1 on PMN to cleavage by elastase, since 10 $\mu \mathrm{g} / \mathrm{ml}$ of neutrophil elastase for $20 \mathrm{~min}$ was required for $50 \%$ cleavage of CR1 (Fig. 1) and only $0.5 \mu \mathrm{g} / \mathrm{ml}$ for $30 \mathrm{~min}$ was needed to achieve a similar effect on C3bi (Fig. 8). Therefore, we performed parallel experiments with both $\mathrm{CR} 1$ and $\mathrm{C} 3 \mathrm{bi}$ to directly compare their sensitivity to elastase. As shown in Fig. 10 , when PMN or opsonized Pa were incubated with various concentrations of neutrophil elastase for $30 \mathrm{~min}, 50 \%$ and $95 \%$ of the bound C3bi on $\mathrm{Pa}$ was cleaved by 0.3 and $1.0 \mu \mathrm{g} / \mathrm{ml}$ of the enzyme, respectively. Cleavage of $60 \%$ and $95 \%$ of the CR 1 on $\mathrm{PMN}$ required 10 and $30 \mu \mathrm{g} / \mathrm{ml}$ of elastase respectively. Thus, C3bi on $\mathrm{Pa}$ was $\sim 30$-fold more sensitive to elastase cleavage than CR1 on PMN. Similar results were obtained with Pseudomonas elastase (not shown).

Comparison of effects of elastase with those of specifically blocking $C R 1$ and $C R 3$ on PMN with anti-receptor antibodies. Although we had demonstrated that elastase cleaved CR1 and

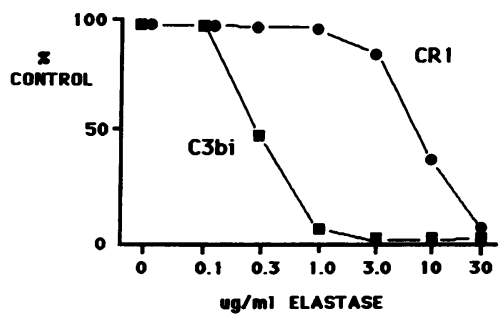

Figure 10. Relative elastase sensitivity of CR1 on PMN vs. C3bi on Pa. PMN $\left(10^{6}\right)$ treated with FMLP and opsonized $\mathrm{Pa}\left(10^{8}\right)$ were incubated in parallel at $37^{\circ} \mathrm{C}$ for $30 \mathrm{~min}$ with neutrophil elastase at the concentrations indicated. CR1 on PMN

and C3bi on Pa were then determined by flow cytometry and enzyme immunoassay, respectively, as described above. The results shown are the percent of the respective control values obtained in the absence of elastase.
C3bi, it is also possible that the enzyme had other effects on the PMN or opsonized $\mathrm{Pa}$ that did not involve complement-derived opsonins or their receptors. To confirm that cleavage of CR1 and C3bi by elastase could account for the degree of inhibition of PMN-Pa interactions observed in these studies we performed similar studies using excess monoclonal antibodies to $\mathrm{CR} 1$ and/or CR3 to block these receptors on the PMN. Table I compares the inhibition of phagocytosis caused by these anti-receptor antibodies to the inhibition caused by elastase cleavage of CR1 on PMN and C3bi on bacteria. As shown, pretreatment of PMN with anti-CR 1 caused a $40 \pm 12 \%$ decrease in phagocytosis of opsonized $\mathrm{Pa}$; this is similar to the decrease caused by treating the PMN alone with elastase. Antibody to the C3bi receptor, CR3, caused $23 \pm 7 \%$ inhibition of phagocytosis; this is similar to the decrease caused by treating the opsonized $\mathrm{Pa}$ alone with elastase. When both antibodies were used together, the effect was roughly additive, $59 \pm 14 \%$ inhibition, which is comparable to the inhibition observed when both the PMN and opsonized Pa were treated with elastase. Thus, whether by blocking the receptors or by cleaving CR1 and C3bi with elastase, interference with both opsoninreceptor pairs, inhibited complement-dependent $\mathrm{PMN}-\mathrm{Pa}$ interactions in an additive fashion.

\section{Discussion}

Most patients with CF develop chronic pulmonary infection due to Pseudomonas aeruginosa $(\mathrm{Pa})$. Despite the fact that no systemic host defense defect has been demonstrated, these patients are unable to clear this infection, even with aggressive antibiotic treatment (1). Local factors thus appear to be responsible for the impaired pulmonary defenses of these patients. Alveolar macrophages, usually the first line of phagocytic defense in the lung (20), are unable to forestall the progression of this infection. As a result of an increasing number of microorganisms and their interaction with the host, PMN are recruited to the lung in greater numbers. These phagocytes become the most numerous cell type in the secretions of most chronically infected CF patients (5) and are the source of a large burden of proteases, particularly elastase (22). PMN rely heavily on complement-mediated opsonization of organisms for optimal phagocytosis, as they express two types of complement receptor, CR1 and CR3, and usually bear only low affinity receptors for the Fc portion of $\operatorname{IgG}(6,21)$. Bound complement (C3) has been demonstrated on bacteria recovered directly from the secretions of chronically infected CF patients (23), further suggesting the potential importance of complement-mediated interactions between $\mathrm{PMN}$ and $\mathrm{Pa}$ in the lungs of these patients.

We showed previously that PMN from CF BAL fluid were markedly deficient in surface expression of CR1, the receptor for the opsonic $\mathrm{C} 3$ fragment, $\mathrm{C} 3 \mathrm{~b}$, but expressed maximal levels of CR3, the PMN receptor for the other major opsonic C3 fragment, C3bi (5). This is in sharp distinction to other situations, both in vitro and in vivo, in which these receptors are upregulated in parallel $(5,24)$. Furthermore, either purified neutrophil elastase or serine protease activity in the supernatants of these CF BAL specimens could cleave CR1 from peripheral blood PMN activated in vitro without affecting CR3 (5). We proposed that such a deficiency in surface CR 1, presumably due to cleavage of this receptor by neutrophil elastase 
Table I. Effect of Monoclonal Antibodies to CR1 and CR3 on Phagocytosis of Opsonized Pa by PMN: Comparison with Elastase Treatment of PMN and Bacteria

\begin{tabular}{|c|c|c|c|}
\hline \multicolumn{2}{|c|}{ Inhibition by antibodies } & \multicolumn{2}{|c|}{ Inhibition by elastase } \\
\hline PMN receptor specificity & $\begin{array}{l}\text { Inhibition of } \\
\text { phagocytosis* }\end{array}$ & Treatment condition (effect) & $\begin{array}{l}\text { Inhibition of } \\
\text { phagocytosis }\end{array}$ \\
\hline & $\%$ & & $\%$ \\
\hline Binding control: CDw32 (IV.3) & 0 & & \\
\hline CR1 (3D9) & $40 \pm 12$ & PMN only treated (CR1 cleaved) & $31 \pm 11$ \\
\hline CR3 (anti-Mol) & $23 \pm 7$ & Bacteria only treated (C3bi cleaved) & $21 \pm 8$ \\
\hline $\mathrm{CR} 1+\mathrm{CR} 3$ & $58 \pm 14$ & Both treated (CR1 and C3bi cleaved) & $54 \pm 20$ \\
\hline
\end{tabular}

* Compared to buffer control in place of antibody or protease; results shown represent mean \pm SE for $n=4$; results for unopsonized bacteria were subtracted as background.

in the inflammatory milieu, would result in defective complement-mediated phagocytic clearance and killing of opsonized bacteria. In the present studies, we found that neutrophil elastase caused marked impairments in the entire spectrum of PMN-Pa interactions including attachment, phagocytosis, stimulation of $\mathrm{PMN} \mathrm{O}_{2}^{-}$production, and bacterial killing. With alternative soluble stimuli for $\mathrm{PMN} \mathrm{O}_{2}^{-}$production such as PMA and LPS, however, elastase had no effect. Thus, the decrease in the metabolic activity stimulated by opsonized $\mathrm{Pa}$ in elastase-treated vs. control PMN must be a consequence of the effects of the enzyme on the surface interactions between the PMN and the bacteria rather than on PMN activation mechanisms per se. We further documented that elastase also cleaves $\mathrm{C} 3$ bi bound on opsonized $\mathrm{Pa}$, and that this action of the enzyme contributes substantially to the overall extent of elastase-induced impairment in PMN-Pa interactions. The cleavage by elastase of both CR1 on PMN and C3bi on opsonized $\mathrm{Pa}$ virtually eliminates the possibility for complement-dependent interactions between PMN and opsonized $\mathrm{Pa}$ by creating an "opsonin-receptor mismatch", since the CR1/C3b opsonin-receptor pair is missing its receptor, CR1; and the CR3/C3bi pair is missing its opsonin, C3bi.

Neutrophil elastase has been shown to cleave other opsonic proteins including IgG, fibronectin, and certain fluid phase complement components $(3,25,26)$, as well as other phagocytic receptors, including the type III Fc receptor on PMN (27). To confirm that complement-mediated processes are the primary functions being affected by elastase in our system, we have used two approaches. First, we showed that blocking CR1 on PMN with specific anti-receptor MAb inhibited phagocytosis of opsonized $\mathrm{Pa}$ to an extent similar to that caused by elastase treatment of PMN, which cleaved the CR1 on these cells. Blocking CR3 with specific MAb reduced phagocytosis of $\mathrm{Pa}$ to an extent similar to that caused by elastase treatment of the opsonized $\mathrm{Pa}$, which cleaved the $\mathrm{C} 3 \mathrm{bi}$ bound on these bacteria. The inhibition of phagocytosis caused by interfering with both $\mathrm{CR} 1 / \mathrm{C} 3 \mathrm{~b}$ and CR3/C3bi opsonin-receptor pairs was roughly additive, whether it was accomplished by cleaving $\mathrm{CR} 1$ and $\mathrm{C} 3$ bi with elastase or by blocking CR1 and CR3 with specific MAbs. Second, when we used excess $\mathrm{Pa}$ to preabsorb the pooled human serum that was used for opsonization, to remove specific antibodies, there was no difference in the results of assays for bound $\mathrm{C} 3$ fragments or phagocytosis of $\mathrm{Pa}$ by PMN, or in the effects of elastase in these assays. Furthermore, we have shown previously that elastase has no effect on IgGmediated phagocytosis or $\mathrm{O}_{2}^{-}$production by $\mathrm{PMN}$, despite the fact that it cleaves one class of IgG Fc receptor (FcR III), because these functions are mediated by an elastase-resistant class of Fc receptors (FcR II) (27). Thus, it is unlikely that effects on Fc receptors or IgG contributed to the elastase-induced impairments in $\mathrm{PMN}-\mathrm{Pa}$ interactions we are reporting here. We are unaware of previous studies that have examined the effects of elastase on PMN-microbe interactions at the opsonin-receptor level, although Hakansson showed that neutrophil elastase reduced complement- but not IgG-mediated, phagocytosis of yeast particles by PMN (28).

We found that $\mathrm{C} 3 \mathrm{bi}$ was cleaved from the surface of opsonized $\mathrm{Pa}$ at concentrations of neutrophil or Pseudomonas elastase $\sim 30$-fold lower than that required to cleave comparable proportions of CR1 from the PMN (Fig. 10). This greater sensitivity of C3bi compared to CR 1 could be important early in the course of the establishment of lung infection when local concentrations of elastase are low but may still be sufficient to interfere with effective opsonization by cleaving C3bi (see below). Furthermore, the finding that 1:10 dilutions of BAL supernatants had activity similar to $1 \mu \mathrm{g} / \mathrm{ml}$ of purified elastase despite the fact that they were already diluted by saline during collection, suggests that in vivo concentrations of neutrophil elastase in CF patients with chronic lung infection easily exceed $10 \mu \mathrm{g} / \mathrm{ml}$ and validates our use of elastase in this concentration range in our studies of CR1 cleavage and inhibition of PMN-Pa interactions.

Production of specific antibodies to Pseudomonas elastase in the lungs of infected CF patients results in formation of immune complexes and neutralization of the activity of this enzyme $(29,30)$. Although the immunoreactive mass of Pseudomonas elastase in the lung secretions of chronically infected CF patients is large, data from other laboratories have been variable regarding the presence of metalloproteinase activity consistent with this enzyme in BAL fluid of chronically infected CF patients $(5,30,31)$. In the current studies, we showed that serine protease inhibitors, but not metalloprotease inhibitors blocked the cleavage of $\mathrm{C} 3$ bi by $\mathrm{CF}$ lung lavage supernatants (Fig. 9). In previous studies in our laboratory, we observed the same pattern for inhibition of $\mathrm{CR} 1$ cleavage by these supernatants (5). Cathepsin G, a chymotrypsin-like serine protease of neutrophils, which has also been found in lung secretions of chronically infected CF patients (25), does not 
produce significant cleavage of $\mathrm{C} 3 \mathrm{bi}$ on $\mathrm{Pa}$ at concentrations comparable to those for elastase used in these studies (Tosi, M. F., unpublished observations). We thus conclude that neutrophil elastase is the predominant if not the sole source of CR1- and C3bi-cleaving activity in the lungs of these chronically infected CF patients.

The microbiology of chronic lung infection in CF patients is quite characteristic. Most of these patients are infected with $P$. aeruginosa (1). Chronic infection in some younger CF patients has been caused by Staphylococcus aureus or untypable Haemophilus influenzae. However, these organisms are eventually supplanted by $P$. aeruginosa in most cases, presumably due in part to a greater likelihood of antibiotic resistance in the latter and to other factors that remain poorly defined (17). When we studied the effects of neutrophil elastase on interactions between PMN and $S$. aureus, $H$. influenzae, E. coli, or $S$. pneumoniae, we obtained results similar to those for $\mathrm{Pa}$. Thus, while the impairment of PMN-Pa interactions by neutrophil elastase is relevant to the CF host, it is not a unique feature of this organism. However, elastase produced by $\mathrm{Pa}$ itself could serve as a special virulence factor for this organism early in the course of infection, before neutralizing antibodies are formed by the host, by cleaving highly elastase-sensitive opsonins as we have demonstrated in this study.

In view of evidence that IgG antibodies against Pseudomonas in CF patients may already be poor opsonins due to altered isotype (32) or cleavage of their Fc portions by elastase in the lung (3), the deficiencies in complement-mediated phagocytic mechanisms we have documented become even more important. The cleavage by elastase of CR1 from PMN and $\mathrm{C} 3 \mathrm{bi}$ from opsonized $\mathrm{Pa}$ results in fewer PMN receptors for the elastase-resistant opsonin, $\mathrm{C} 3 \mathrm{~b}$, and fewer opsonic ligands on the bacteria for CR3, which also remains intact. Thus, even though one receptor and one opsonic ligand remain intact, there is a marked deficiency in potential opsonin-receptor pairs. We have termed this situation an "opsonin-receptor mismatch". This effect results in markedly impaired phagocytosis and killing of these bacteria. This evidence of the additional pathologic effects of excess protease activity in the chronically infected lungs of CF patients suggests a potential role for protease inhibitors, such as alpha-1antitrypsin, as therapeutic agents which might moderate this and other adverse effects of neutrophil elastase in the lung $(33,34)$.

\section{Acknowledgments}

Supported by grants from the Cystic Fibrosis Foundation and by grants HL-02234, AI-22687, and DK-27651 from the National Institutes of Health. Dr. Berger is a Research Scholar of the Cystic Fibrosis Foundation.

\section{References}

1. Schreiber, J. R., and D. A. Goldmann. 1986. Infections complicating cystic fibrosis. In Current Clinical Topics in Infectious Disease. Vol. 7. J. S. Remington, and M. N. Swartz, editors. McGraw-Hill, New York. 51-81.

2. Thomassen, M. J., C. A. Demko, R. E. Wood, B. Tandler, D. G. Dearborn, B. Boxerbaum, and P. J. Kuchenbrod. Ultrastructure and function of alveolar macrophages from cystic fibrosis patients. Pediatrics. 14:715-721.
3. Fick, R. B., Jr., G. P. Naegel, S. U. Squier, R. E. Wood, J. B. L. Gee, and H. Y. Reynolds. 1984. Proteins of the cystic fibrosis respiratory tract, fragmented IgG opsonin activity causing defective opsonophagocytosis. J. Clin. Invest. 4:236-248.

4. Welsh, M. J., and R. B. Fick. 1987. Cystic fibrosis. J. Clin. Invest. 80:1523-1526.

5. Berger, M., R. U. Sorensen, M. F. Tosi, D. G. Dearborn, and G. Döring. 1989. Complement receptor expression on neutrophils at an inflammatory site, the Pseudomonas-infected lung in cystic fibrosis. $J$. Clin. Invest. 84:1302-1313.

6. Joiner, K. A., E. J. Brown, and M. M. Frank. 1984. Complement and bacteria: chemistry and biology in host defense. Annu. Rev. Immunol. 2:461-491.

7. Carlo, J. R., J. K. Spitznagel, F. J. Studer, D. H. Conrad, and S. Ruddy. 1981. Cleavage of membrane bound C3bi, an intermediate of the third component of complement, to $\mathrm{C} 3 \mathrm{c}$ and $\mathrm{C} 3 \mathrm{~d}$-like fragments by crude leukocyte lysosomal lysates and purified leukocyte elastase. Immunology. 44:381-391.

8. Tosi, M. F., D. C. Anderson, J. Barrish, E. O. Mason, Jr., and S. L. Kaplan. 1985. Effect of piliation on interactions of Haemophilus influenzae type b with human polymorphonuclear leukocytes. Infect. Immun. 4:777870-785.

9. Mayer, M. M. 1971. Complement and complement fixation. In Experimental immunochemistry. E. A. Kabat, editor. Charles C. Thomas Publisher, Springfield, IL. 133-240.

10. Berger, M., J. O'Shea, A. S. Cross, T. M. Folks, T. M. Chused, E. J. Brown, and M. M. Frank. 1984. Human neutrophils increase expression of $\mathrm{C} 3 \mathrm{bi}$ as well as $\mathrm{C} 3 \mathrm{~b}$ receptors upon activation. J. Clin. Invest. 74:1566-1571.

11. Looney, R. J., D. H. Ryan, K. Takahashi, H. B. Fleit, H. J. Cohen, G. N. Abraham, and C. L. Anderson. 1986. Identification of a second class of IgG Fc receptors on human neutrophils. A 40 kilodalton molecule also found on eosinophils. J. Exp. Med. 163:826-836.

12. Berger, M., and M. E. Medof. 1987. Increased expression of complement decay-accelerating factor during activation of human neutrophils. J. Clin. Invest. 79:214-220.

13. Sveum, R. J., T. M. Chused, M. M. Frank, and E. J. Brown. 1986. A quantitative fluorescent method for measurement of bacterial adherence and phagocytosis. J. Immunol. Methods. 90:257-264.

14. Davies, P., R. I. Fox, M. Polyzonis, A. C. Allison, and A. D. Haswell. 1973. The inhibition of phagocytosis and facilitation of exocytosis in rabbit polymorphonuclear leukocytes by cytochalasin B. Lab. Invest. 28:16-25.

15. Minkenberg, I., and E. Ferber. 1984. Lucigenin-dependent chemiluminescence as a new assay for NADPH oxidase activity in particulate fractions of human polymorphonuclear leukocytes. J. Immunol. Methods. 71:61-67.

16. Babior, B. M., R. S. Kipnes, and J. T. Curnuette. 1973. Biological defense mechanisms. The production by leukocytes of superoxide, a potential bactericidal agent. J. Clin. Invest. 52:741-744.

17. Pier, G. B. 1985. Pulmonary disease associated with Pseudomonas aeruginosa in cystic fibrosis: current status of the host-bacterium interaction. J. Infect. Dis. 151:575-580.

18. Quie, P. G., J. G. White, B. Holmes, and R. A. Good. 1967. In vitro bactericidal capacity of human polymorphonuclear leukocytes. Diminished activity in chronic granulomatous disease of childhood. $J$. Clin. Invest. 46:648-649.

19. Engels, W., J. Endert, and C. P. A. Van Bouen. 1985. A quantitative method for assessing the third complement factor (C3) attached to the surface of opsonized Pseudomonas aeruginosa. Interrelationship between $\mathrm{C} 3$ fixation, phagocytosis, and complement consumption. J. Immunol. Methods. 81:43-45.

20. Goldstein, E., W. Lippert, and K. Warshauer. 1974. Pulmonary alveolar macrophage. Defender against bacterial infection of the lung. J. Clin. Invest. 54:519-528.

21. Anderson, C. L., and R. J. Looney. 1986. Human leukocyte IgG Fc receptors. Immunol. Today. 7:264-266. 
22. Döring, G., W. Goldstein, K. Botzenhart, A. Kharazmi, P. O. Schiotz, N. Hoiby, and M. Dasgupta. 1986. Elastase from polymorphonuclear leucocytes: a regulatory enzyme in immune complex disease. Clin. Exp. Immunol. 64:597-605.

23. Hann, S., and D. S. Holsclaw. 1978. Interactions of Pseudomonas aeruginosa with immunoglobulins and complement in sputum. Infect. Immun. 14:114-117.

24. Moore, Jr., F. D., C. Davis, M. Rodrick, J. A. Mannick, and D. T. Fearon. 1986. Neutrophil activation in thermal injury as assessed by increased expression of complement receptors. N. Engl. J. Med. 314:948-953.

25. Suter, S., U. B. Schaad, J. J. Morgenthaler, I. Chevallier, and H. P. Schnebli. 1988. Fibronectin-cleaving activity in bronchial secretions of patients with cystic fibrosis. J. Infect. Dis. 158:89-100.

26. Suter, S., U. E. Nydegger, L. Roux, and F. A. Waldvogel. 1981. Cleavage of $\mathrm{C} 3$ by neutral proteases from granulocytes in pleural empyema. J. Infect. Dis. 144:499-508.

27. Tosi, M., and M. Berger. 1988. Functional differences between the $40 \mathrm{kDa}$ and 50 to $70 \mathrm{kDa}$ IgG Fc receptors on human neutrophils revealed by elastase treatment and antireceptor antibodies. J. Immunol. 141:2097-2103.

28. Hakansson, L., and P. Venge. 1982. Kinetic stùdies of neutro- phil phagocytosis. V. Studies on the co-operation between the Fc and C3b receptors. Immunology. 47:687-694.

29. Döring, G., W. Goldstein, A. Roll, P. O. Schiotz, N. Hoiby, and K. Botzenhart. 1985. Role of Pseudomonas aeruginosa exoenzymes in lung infections of patients with cystic fibrosis. Infect. Immun. 49:557562.

30. Döring, G., V. Buhl, N. Hoiby, P. O. Schiotz, and K. Botzenhart. 1984. Detection of proteases of Pseudomonas aeruginosa in immune complexes isolated from sputum of cystic fibrosis patients. Acta Path. Microbiol. Immunol. Scand. 92:307-312.

31. Fick, R. B., D. B. Hornick, and S. I. Rennard. 1987. Contribution of Pseudomonas elastase to the protease burden in cystic fibrosis airways. Clin. Invest. 35:533A.

32. Moss, R. B., W. P. Hsu, M. M. Sullivan, and N. J. Lewiston. 1986. Altered antibody isotype in cystic fibrosis: Possible role in opsonic deficiency. Pediatr. Res. 20:453-459.

33. Bruce, M., L. Poncz, J. D. Klinger, R. C. Stern, J. F. Tomashefski, Jr., and D. G. Dearborn. 1985. Biochemical and pathologic evidence for proteolytic destruction of lung connective tissue in cystic fibrosis. Am. Rev. Respir. Dis. 132:529-535.

34. Janoff, A. 1985. Elastase and Emphysema. Current assessment of the protease-antiprotease hypothesis. Am. Rev. Respir. Dis. 132:417-433. 